\title{
DESENVOLVIMENTO E VALIDAÇÃO DE MÉTODO ESPECTROFOTOMÉTRICO PARA DETERMINAÇÃO DE CORANTE À BASE DE LUTEÍNA ADICIONADO EM IOGURTE DESNATADO
}

\author{
Ana Augusta Odorissi Xavier e Adriana Zerlotti Mercadante* \\ Departamento de Ciência de Alimentos, Faculdade de Engenharia de Alimentos, Universidade Estadual de Campinas, Rua Monteiro \\ Lobato, 80, 13083-862 Campinas - SP, Brasil \\ Lígia Dozena Domingos e Walkíria Hanada Viotto \\ Departamento de Tecnologia de Alimentos, Faculdade de Engenharia de Alimentos, Universidade Estadual de Campinas, Rua \\ Monteiro Lobato, 80, 13083-862 Campinas - SP, Brasil
}

Recebido em 3/2/12; aceito em 2/7/12; publicado na web em 31/8/12

\begin{abstract}
DEVELOPMENT AND VALIDATION OF A SPECTROPHOTOMETRIC METHOD FOR DETERMINATION OF LUTEIN COLORANT ADDED TO NONFAT YOGURT. A simple analytical method for extraction and quantification of lutein colorant added to yogurt was developed and validated. The method allowed complete extraction of carotenoids using tetrahydrofuran in vortex, followed by centrifugation, partition to diethyl ether/petroleum ether, and drying. The carotenoids dissolved in ethanol were quantified by UV-Vis spectrophotometry. This method showed linearity in the range tested (1.41-13.42 $\left.\mu \mathrm{g} \mathrm{g}^{-1}\right)$, limits of detection and quantification of 0.42 and $1.28 \mu \mathrm{g} \mathrm{g}^{-1}$, respectively, low relative standard deviation (3.4\%) and recovery ranging from 95 to $103 \%$. The method proved reliable for quantification of lutein added to yogurt.
\end{abstract}

Keywords: UV-Vis spectroscopy; yogurt; lutein colorant.

\section{INTRODUÇÃO}

Os carotenoides são pigmentos sintetizados por plantas superiores, microrganismos e alguns animais, com coloração que varia do amarelo ao vermelho. Sua estrutura terpenoide apresenta um extenso sistema de ligações duplas conjugadas, que é responsável tanto por sua capacidade de absorver luz na região do visível quanto por sua elevada reatividade química. ${ }^{1}$ Os carotenoides são conhecidos por seu emprego como corantes e também por sua atividade biológica, e seu consumo tem sido inversamente correlacionado com a ocorrência de doenças crônico-degenerativas. ${ }^{2}$ Dentre estes pigmentos, a luteína se destaca pela sua associação com a diminuição da ocorrência e prevenção da catarata e da degeneração macular relacionada à idade (DMRI). ${ }^{3-5}$ A DMRI caracteriza-se pela degradação da porção central da retina e é a maior causa de cegueira irreversível em idosos. ${ }^{6}$

O leite e seus derivados são produtos bastante aceitos pelo mercado consumidor por estarem relacionados a hábitos alimentares ditos "saudáveis", já que são fontes de cálcio, proteínas e vitaminas A e E. ${ }^{7}$ Tendo em vista o crescimento do mercado de produtos derivados do leite e de alimentos funcionais, ${ }^{8}$ os produtos lácteos se apresentam como potenciais veículos de adição de substâncias benéficas à saúde, como a luteína, considerando a relação inversa entre o consumo deste carotenoide e o desenvolvimento de DMRI.

A análise quantitativa de carotenoides em iogurte e outras matrizes lácteas envolve várias etapas, incluindo a extração com solventes de baixa polaridade, saponificação e posterior separação dos compostos por cromatografia líquida de alta eficiência em fase reversa, geralmente acoplada a um detector de arranjo de diodos (CLAE-DAD) ${ }^{9-11}$ Esta técnica permite a detecção e quantificação de cada composto separadamente, mas com as desvantagens de maior tempo de análise, alto custo do equipamento e a necessidade de um extrato livre de impurezas. Por outro lado, o método clássico de quantificação de carotenoides por espectrofotometria na região do UV-visível ainda tem sido empregado em diversas matrizes,

*e-mail: azm@fea.unicamp.br principalmente naquelas ricas em um carotenoide específico, onde se utiliza o comprimento de onda de absorção máxima do carotenoide majoritário e seu correspondente coeficiente de absortividade. ${ }^{12}$ Além disso, os parâmetros analíticos do método devem ser adequados à intenção de uso do mesmo, ou seja, um método para análise de compostos presentes em elevadas concentrações, como o corante luteína adicionado ao iogurte, não requer a mesma sensibilidade de um método desenvolvido para análise de traços. ${ }^{13}$

O corante natural à base de luteína adicionado aos iogurtes preparados neste estudo constitui uma matriz bastante complexa pois contém, além de carotenoides, amido modificado, ácido ascórbico, palmitato de ascorbila, alfa-tocoferol, benzoato de sódio, óleo de girassol e maltodextrina. Devido à presença de óleos vegetais, para realizar a análise do corante por CLAE é necessário saponificar os extratos com uma concentração de álcali maior que a usual $(10 \% \mathrm{KOH})$, o que pode levar a perdas e consequente subestimação do teor de carotenoides. ${ }^{14}$ Além disso, a luteína extraída das flores de Tagetes erecta L. (família Asteraceae), fonte da luteína presente no corante, encontra-se predominantemente esterificada com ácidos graxos, o que corrobora a necessidade de uma etapa de saponificação dos extratos. ${ }^{15} \mathrm{O}$ aumento de etapas no procedimento de extração do corante eleva tanto o custo quanto o tempo de análise, inviabilizando a aplicação do método em estudos de estabilidade da luteína em iogurte. A introdução de novas etapas também implica em provável aumento do desvio padrão relativo, o que é indesejável quando se trata da avaliação de mudanças de concentração de um composto durante o período de armazenamento.

O objetivo do presente estudo foi desenvolver e validar um método simples, de baixo custo e reprodutível para extração e quantificação por espectrofotometria UV-visível de carotenoides em iogurte adicionado de corante natural à base de luteína.

\section{PARTE EXPERIMENTAL}

\section{Materiais e equipamentos}

O leite em pó desnatado Molico ${ }^{\circledR}$ (Nestlé - Araçatuba, Brasil) 
foi adquirido em um supermercado na cidade de Campinas (Brasil), sendo todo do mesmo lote. A cultura láctea liofilizada, constituída de Streptococcus thermophilus e Lactobacillus bulgaricus (YO-MIX 505 LYO $200^{\circledR}$ ), foi fornecida pela Danisco (Cotia, Brasil). O corante natural à base de luteína Vegex Lutein WS ${ }^{\circledR}$ foi adquirido da Christian Hansen (Horsholm, Dinamarca). Esta formulação contém 0,3\% de luteína, possui características hidrofílicas e é utilizada para fins alimentícios. A protease bacteriana Protex $6 \mathrm{~L}^{\circledR}$ (Genencor Int., Rochester, EUA) foi cedida pela Danisco (Tonder, Dinamarca). Os solventes acetona, acetato de etila, etanol, éter etílico, éter de petróleo, metanol e tetraidrofurano, todos de grau analítico, foram adquiridos da Synth (Diadema, Brasil), assim como o sulfato de sódio anidro e hidróxido de potássio $(\mathrm{KOH})$. Os solventes acetonitrila, metanol e acetato de etila, todos grau CLAE, foram adquiridos da J. T. Baker (Phillipsburg, EUA). O padrão de luteína com pureza de $99 \%$ foi doado pela DSM Nutritional Products (Basel, Suíça). Previamente à análise por CLAE, os extratos e solventes foram filtrados em membrana de polietileno de 0,22 e 0,45 $\mu \mathrm{m}$, respectivamente, da Millipore (Billerica, EUA).

A fermentação dos iogurtes foi realizada em estufa Marconi modelo MA 415/S (Piracicaba, Brasil). Para extração dos carotenoides foram utilizados mesa agitadora orbital Marconi modelo MA140/T (Piracicaba, Brasil), homogeneizador de bancada Marconi modelo MA102 (Piracicaba, Brasil), agitador de soluções tipo vortex Phoenix Luferco, modelo AP56 (Araraquara, Brasil), centrífuga Beckman Coulter, modelo Allegra ${ }^{\circledR}$ 64R (Brea, EUA) e evaporador rotatório Buchi (Flawil, Suíça). A quantificação foi realizada em espectrofotômetro com arranjo de diodos Agilent, modelo 8453 (Palo Alto, EUA).

A análise dos carotenoides do corante à base de luteína adicionado ao iogurte foi realizada por CLAE, utilizando um equipamento modelo 600E da Waters (Milford, EUA) equipado com detector de arranjo de diodos (DAD) Waters modelo 996, sistema desgaseificador, sistema de injeção Rheodyne com alça de amostra de $20 \mu \mathrm{L}$ (Rohnert Park, EUA) e sistema de aquisição e processamento de dados Millenium.

\section{Métodos}

Análise por CLAE de carotenoides do corante à base de luteína

O corante $(0,05 \mathrm{~g})$ foi dissolvido em $1 \mathrm{~mL}$ de água destilada e os carotenoides foram exaustivamente extraídos em vortex, utilizando éter etílico $(2 \mathrm{~mL})$, seguido de acetato de etila $(4 \mathrm{~mL})$. Após cada extração, o extrato foi centrifugado para separação de fases e a fase orgânica foi coletada, seca sob fluxo de nitrogênio, redissolvida em acetato de etila/acetonitrila $\left(1: 1, \mathrm{vv}^{-1}\right)$ e analisada por CLAE. O extrato remanescente foi seco, redissolvido em éter de petróleo e saponificado com igual volume de solução metanólica $10 \%$ de KOH. ${ }^{16}$ Após retirada do álcali, o extrato saponificado foi seco e analisado nas mesmas condições utilizadas para o extrato bruto (não saponificado).

Os carotenoides dos extratos bruto e saponificado foram separados em coluna $\mathrm{C}_{18}$ NovaPak de 300 x 3,9 mm (tamanho de partícula $4 \mu \mathrm{m})$, usando como fase móvel acetonitrila/metanol $\left(9: 1, \mathrm{vv}^{-1}\right)$ e acetato de etila, com gradiente linear de acetato de etila de 0 a $100 \%$ em $30 \mathrm{~min}$. O fluxo empregado foi de $1 \mathrm{~mL} \mathrm{~min}^{-1}$ e a temperatura da coluna foi mantida a $29^{\circ} \mathrm{C}$. Os espectros de absorção UV-visível foram adquiridos entre 200 e $600 \mathrm{~nm}$ e os cromatogramas foram processados a $450 \mathrm{~nm} .{ }^{17}$ Os picos foram identificados com base na ordem de eluição em coluna $\mathrm{C}_{18}$ e nas seguintes características do espectro UV-visível: $\lambda_{\max }$, estrutura fina espectral calculada como percentagem das alturas (III/II)\% e intensidade do pico $\mathrm{cis}$ calculada como $\left(\mathrm{A}_{\mathrm{B}} / \mathrm{A}_{\mathrm{II}}\right) \%$, assinaladas na Figura $1,{ }^{16}$ comparando com informações disponíveis na literatura. ${ }^{15,17-19}$

\section{Produção dos iogurtes}

O leite em pó desnatado foi reconstituído a $10 \%$ de sólidos

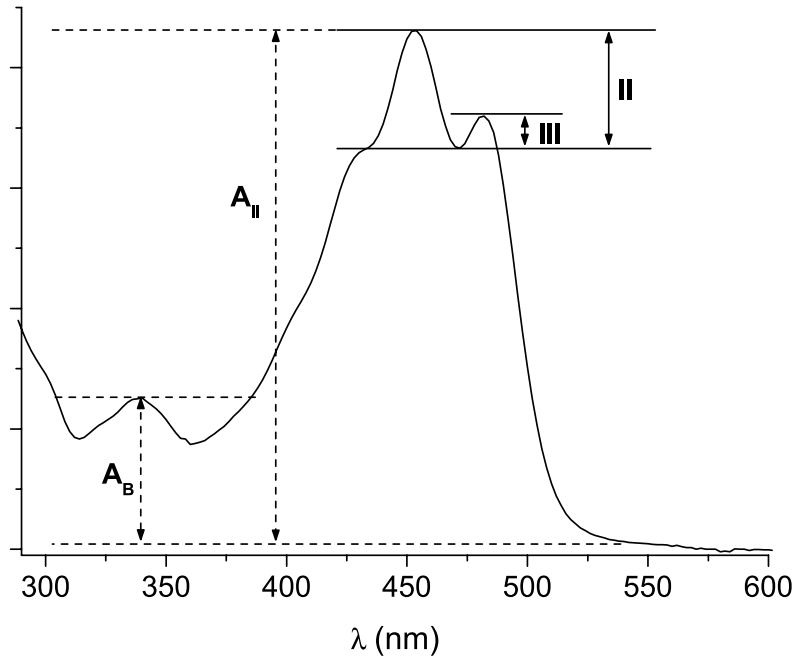

Figura 1. Parâmetros utilizados para cálculo da estrutura fina e intensidade do pico cis do espectro UV-visível de carotenoide

totais e adicionado de 2,5\% da cultura previamente ativada. Em seguida, a formulação de luteína foi adicionada nas concentrações posteriormente descritas nos ensaios dos parâmetros de validação. $\mathrm{O}$ leite foi distribuído em copos plásticos, selados por termo indução, e incubados em estufa a $45^{\circ} \mathrm{C}$, onde permaneceram até atingir $\mathrm{pH} 4,8$ (aproximadamente durante $3 \mathrm{~h}$ ). Os copos foram então resfriados em banho de gelo e armazenados a $5^{\circ} \mathrm{C}$ para as análises posteriores. Um iogurte controle, sem adição do corante à base de luteína, também foi produzido e armazenado utilizando o mesmo procedimento de fabricação e as mesmas condições previamente descritas.

\section{Extração dos carotenoides}

Para extração dos carotenoides totais, os solventes testados foram acetona, acetato de etila e tetraidrofurano, combinados aos seguintes equipamentos para extração: mesa agitadora, homogeneizador, agitador tipo vortex e almofariz. As combinações de solvente e equipamento de extração foram realizadas de acordo com métodos já existentes na literatura para determinação de carotenoides em leite e produtos lácteos. ${ }^{9-11,20} \mathrm{~A}$ necessidade do emprego de uma etapa de saponificação dos extratos, com 10\% de KOH em solução metanólica, também foi verificada. ${ }^{9,10,20}$

Após cada extração, o solvente foi completamente evaporado e o extrato seco foi redissolvido em etanol para a quantificação dos carotenoides totais.

\section{Quantificação dos carotenoides totais}

A determinação dos carotenoides totais foi realizada por espectrofotometria no UV-visível, pela leitura da absorbância do extrato etanólico de carotenoides no comprimento de onda de $445 \mathrm{~nm}, \lambda_{\max }$ de absorção da luteína em etanol. A concentração de carotenoides totais foi calculada a partir da Lei de Lambert-Beer:

$$
C\left(\mu g m L^{-I}\right)=\frac{A \times 10^{4}}{E_{1 \mathrm{~cm}}^{1 \%}}
$$

onde C é a concentração de carotenoides totais (expressa como luteína), A é a absorbância do extrato a $445 \mathrm{~nm}$ e $E_{1 \mathrm{~cm}}^{1 \%}$ é o coeficiente de absortividade da luteína em etanol, que corresponde a $2550 .{ }^{18}$

A determinação de carotenoides totais também foi realizada no iogurte controle para verificar se a concentração de carotenoides presente neste iogurte interfere na quantificação de carotenoides totais no iogurte adicionado de corante luteína. 
Validação do método de extração

Após o teste das diferentes combinações entre solventes e equipamentos para extração dos carotenoides, o método que apresentou os melhores resultados foi validado através dos parâmetros de seletividade, linearidade, faixa de aplicação, limites de detecção e de quantificação, precisão e exatidão. ${ }^{13,21}$

A seletividade do método foi avaliada através da comparação de três espectros de absorção no UV-visível: do padrão de luteína, de um extrato obtido a partir de um iogurte adicionado de corante à base de luteína e de um extrato preparado a partir do iogurte controle. A concentração do padrão de luteína utilizada foi $2,47 \mu \mathrm{g} \mathrm{mL}^{-1}$ e a do extrato de iogurte adicionado de luteína de $1,22 \mu \mathrm{g}$ de luteína $\mathrm{mL}^{-1}$ (que equivale à concentração aproximada de 11,20 $\mu \mathrm{g}$ de luteína $\mathrm{g}^{-1}$ de iogurte, quando extraída de $1 \mathrm{~g}$ do produto e diluída em $10 \mathrm{~mL}$ de etanol, que são condições fixadas pelo método).

A linearidade do método e a faixa de trabalho foram verificadas através de uma curva analítica construída com extratos de carotenoides obtidos a partir de iogurtes adicionados de diferentes concentrações do corante à base de luteína, na faixa de 1,41 a 13,42 $\mu \mathrm{g}$ de luteína $\mathrm{g}^{-1}$ de iogurte. A faixa de concentração dos testes foi definida a fim de contemplar um maior número de concentrações inferiores à concentração média de luteína no iogurte (aproximadamente 11,20 $\mu \mathrm{g} \mathrm{g}^{-1}$ ), uma vez que o objetivo do método é acompanhar os teores de luteína durante o armazenamento do iogurte e a tendência é que a concentração diminua com o decorrer do tempo.

Os limites de detecção (LD) e de quantificação (LQ) foram determinados a partir dos parâmetros da curva analítica construída para o ensaio de linearidade, e foram expressos em $\mu \mathrm{g} \mathrm{g}^{-1} .^{13}$

A precisão foi determinada através da concordância dos resultados no mesmo laboratório, de um mesmo analista, em dias diferentes. Foram realizadas três extrações em 3 dias diferentes a partir de uma mesma amostra de iogurte adicionado do corante à base de luteína na concentração de $11,49 \mu \mathrm{g}$ de luteína $\mathrm{g}^{-1}$ de iogurte, que corresponde à concentração média inicial de luteína adicionada ao iogurte. A precisão foi expressa como desvio padrão relativo (DPR). ${ }^{13}$

A exatidão foi verificada por ensaios de recuperação em iogurtes adicionados de diferentes concentrações conhecidas de corante à base de luteína. Foram utilizados três níveis de adição $(5,53 ; 11,49$ e 13,45 $\mu \mathrm{g}$ de luteína $\mathrm{g}^{-1}$ de iogurte), sendo as extrações realizadas em triplicata em cada nível de adição. Essas concentrações foram utilizadas porque correspondem aproximadamente a 50, 100 e $125 \%$ da concentração média de luteína nos iogurtes.

\section{RESULTADOS E DISCUSSÃO}

\section{Perfil de carotenoides do corante à base de luteína por CLAE-DAD}

O cromatograma dos carotenoides do extrato não saponificado do corante demonstrou a presença de pelo menos oito ésteres de luteína (Figura 2a), enquanto no extrato saponificado (Figura 2b) foi encontrado apenas o pico da luteína. Este resultado já era esperado, pois a presença de mais de $90 \%$ da luteína na forma esterificada em flores de Tagetes erecta L. foi previamente relatada. ${ }^{15,17}$ Os ésteres presentes no corante à base de luteína foram classificados em mono e di-ésteres (Figura 2a), por comparação dos tempos de retenção com dados da literatura. ${ }^{15,17}$ Como não há padrões de ésteres de luteína disponíveis comercialmente, o fato de toda a luteína presente no corante estar esterificada confirma a necessidade de uma etapa de saponificação dos extratos para a quantificação por CLAE e justifica a escolha de um método espectrofotométrico para emprego na quantificação de luteína adicionada em iogurte.

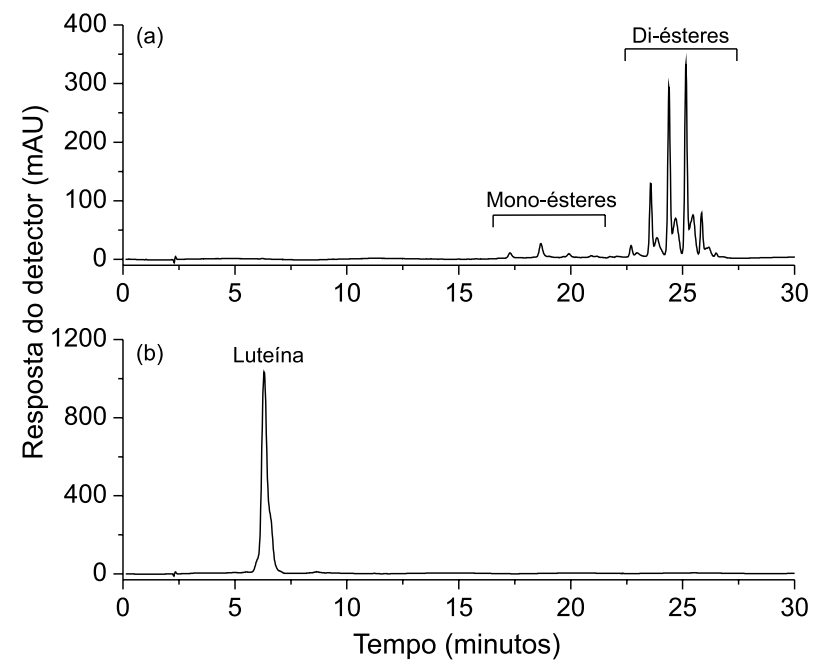

Figura 2. Cromatograma, obtido por CLAE-DAD, do extrato não saponificado (a) e do extrato saponificado (b) de carotenoides do corante à base de luteína. As condições cromatográficas estão descritas no texto

\section{Desenvolvimento do método analítico}

A escolha do melhor solvente para extração depende da composição da matriz e de sua composição de carotenoides. Para extração de carotenoides de matrizes com alto teor de umidade, como o iogurte, é mais apropriado o emprego de solventes com polaridade intermediária e, por isso, foram escolhidos acetato de etila, acetona e tetraidrofurano.

\section{Acetato de etila}

A primeira escolha de solvente foi o acetato de etila, já utilizado anteriormente na extração de luteína adicionada em iogurte desnatado..$^{10}$ Este solvente foi inicialmente testado utilizando uma mesa agitadora como equipamento para extração, seguida de centrifugação para separação de fases. Entretanto, este procedimento não possibilitou a extração completa dos carotenoides, fato verificado visualmente, já que ao término da extração, a amostra ainda mantinha a coloração amarelada.

Um homogeneizador foi então empregado, visando um maior contato entre a amostra e o solvente. Como ocorrido no ensaio em mesa agitadora, a extração com homogeneizador não foi completa.

Como a formulação de luteína adicionada ao iogurte é hidrossolúvel e o iogurte apresenta um elevado teor de umidade, é possível que o fato de o acetato de etila ser um solvente imiscível com água tenha resultado na extração incompleta. Consequentemente, optou-se pelo emprego de solventes miscíveis com a água, como acetona e tetraidrofurano.

\section{Acetona}

Este solvente já foi utilizado em outro estudo para extração de carotenoides em queijo ${ }^{9}$ e também tem sido amplamente empregado na extração de outras matrizes, como frutas e vegetais. ${ }^{16,22,23}$ Para os testes com acetona, o uso de mesa agitadora foi descartado. Foram realizadas extrações em homogeneizador e almofariz, ambas resultando em valores de recuperação de carotenoides totais inferiores a $80 \%$. Em seguida, foi testado o vortex, escolhido pela praticidade do uso e para tentar minimizar perdas de material. Entretanto, a combinação acetona e vortex também gerou resultados insatisfatórios, pois produziu um extrato turvo, provavelmente pela presença de proteínas que devem ter sido extraídas juntamente com os carotenoides. 


\section{Tetraidrofurano}

As proteínas são capazes de formar complexos com os carotenoides e o único solvente capaz de romper este complexo é o tetraidrofurano. ${ }^{24}$ Este solvente já foi empregado para extração de carotenoides de leite e produtos lácteos. ${ }^{11}$ Devido à praticidade do uso do vortex, os testes com tetraidrofurano foram realizados neste equipamento.

Os extratos obtidos com tetraidrofurano apresentaram índices de recuperação de carotenoides maiores que $90 \%$, razão pela qual foram utilizados para se verificar a necessidade da etapa de saponificação. Os extratos foram transferidos para uma mistura de éter etílico e éter de petróleo $\left(2: 1, \mathrm{vv}^{-1}\right)$ em funil de separação, e lavados com cerca de $5 \mathrm{~L}$ de água destilada. Foi adicionada uma solução metanólica $10 \%$ de $\mathrm{KOH}$, na proporção $1: 1\left(\mathrm{vV}^{-1}\right)$ aos extratos etéreos, e estes foram mantidos sob agitação, por $16 \mathrm{~h}$ a $84 \mathrm{rpm}$ à temperatura ambiente, em mesa agitadora. Após a saponificação, o extrato foi novamente particionado para éter etílico e éter de petróleo $\left(2: 1, \mathrm{vv}^{-1}\right)$ e lavado com água destilada até todo o álcali ser removido $(\mathrm{pH}$ da água de lavagem próximo de 7). A etapa de saponificação foi responsável por perdas de carotenoides que variaram de 22 a $41 \%$ e estes resultados corroboram dados existentes na literatura, que relatam perdas consideráveis de carotenoides devido a esta reação..$^{14,24,25}$ No presente trabalho, o extrato obtido com tetraidrofurano apresentou-se límpido no solvente utilizado para quantificação (etanol). Consequentemente, não há necessidade da inclusão de uma etapa de saponificação no procedimento de extração.

O método que permitiu uma completa extração dos carotenoides da amostra de iogurte está apresentado na Figura 3. Em função do iogurte possuir elevado teor de proteína (cerca de 38\%, base seca), o tetraidrofurano mostrou-se um solvente adequado para extração de carotenoides nesta matriz, por ser capaz de desnaturar complexos de

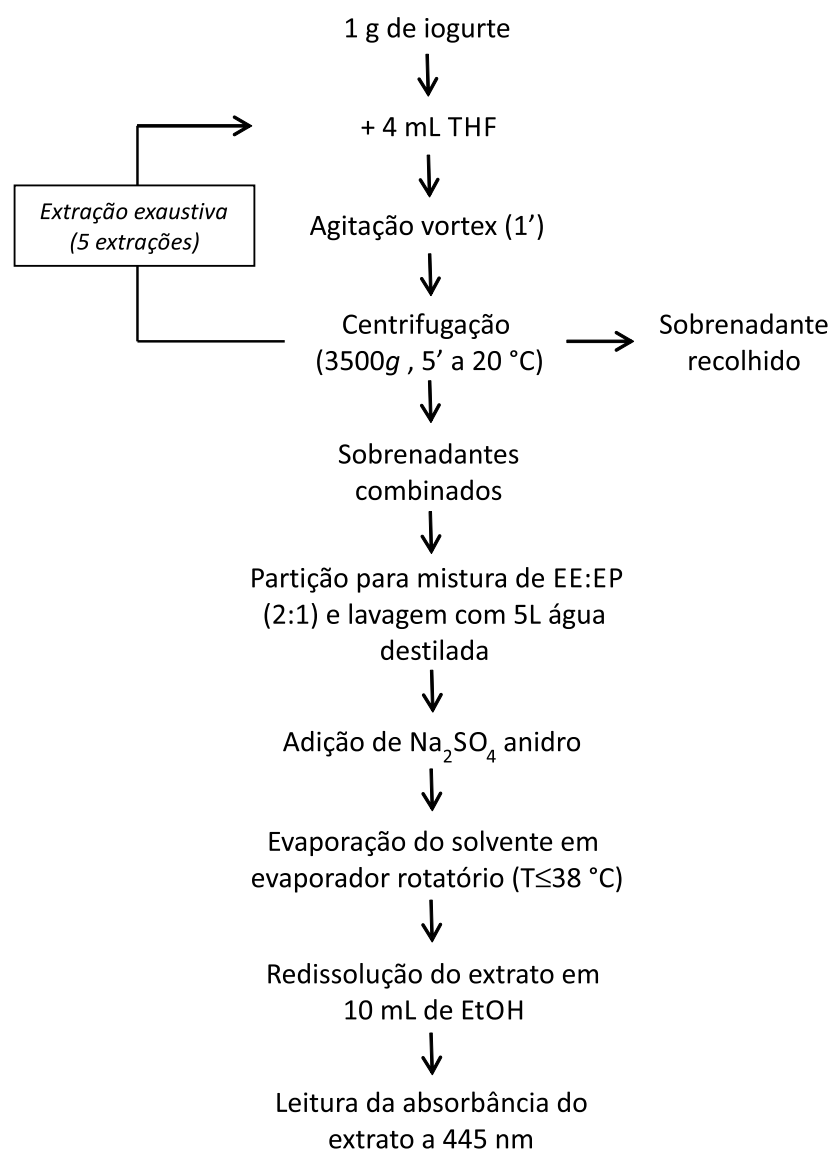

Figura 3. Fluxograma para extração e quantificação de carotenoides totais em iogurte proteínas com carotenoides, facilitando a liberação dos pigmentos e evitando a formação de emulsão durante a extração. ${ }^{24}$ A agitação em vortex proporcionou maior recuperação dos carotenoides, por permitir que o solvente fosse separado do resíduo sólido por centrifugação no mesmo tubo onde a amostra foi extraída, diminuindo a possibilidade de perda de amostra.

Quando o objetivo da análise é a quantificação, é necessária uma extração completa e exaustiva da matriz. No método proposto, a remoção completa dos carotenoides foi alcançada após cinco extrações, já que a partir da sexta extração os extratos não apresentaram banda de absorção no comprimento de onda de $445 \mathrm{~nm}$.

É sabido que o extrato de carotenoides obtido por solventes miscíveis com a água, como é o caso do tetraidrofurano, contém elevados teores de água, além de compostos hidrossolúveis presentes na matriz. ${ }^{1}$ Com o intuito de remover a água, compostos polares e o solvente foi realizada a partição do extrato para uma mistura de éter etílico e éter de petróleo, na proporção 2:1 $\left(\mathrm{vv}^{-1}\right)$, seguida de lavagem com água destilada. Esta proporção foi utilizada devido à presença majoritária da luteína no extrato obtido a partir do iogurte, pois como este carotenoide possui dois grupos hidroxila em sua estrutura (Figura 4), é preferencialmente solúvel em éter etílico do que em éter de petróleo. Posteriormente à etapa de partição, foi adicionado sulfato de sódio anidro para retirada de resíduos da água de lavagem. Em seguida, o éter foi totalmente evaporado em evaporador rotatório, com temperatura do banho inferior a $38^{\circ} \mathrm{C}$, uma vez que os carotenoides são suscetíveis à isomerização em temperaturas elevadas. ${ }^{26} \mathrm{O}$ extrato seco foi redissolvido em etanol e, imediatamente, procedeu-se à leitura da absorbância para quantificação dos carotenoides totais, seguindo o procedimento descrito anteriormente.<smiles>CC1=C[C@H](O)CC(C)(C)[C@H]1/C=C/C(C)=C/C=C/C(C)=C/C=C/C=C(C)/C=C/C=C(C)/C=C/C1=C(C)C[C@@H](O)CC1(C)C</smiles>

Figura 4. Estrutura química da luteína

\section{Validação do método}

O teor de carotenoides totais do iogurte controle foi inferior ao limite de quantificação do método desenvolvido $\left(1,28 \mu \mathrm{g} \mathrm{g}^{-1}\right)$, comprovando que não houve interferência dos carotenoides provenientes do leite desnatado na quantificação dos carotenoides totais do iogurte adicionado de corante luteína.

A seletividade de um método consiste na capacidade de medir um composto na presença de outros componentes ou substâncias interferentes. ${ }^{21}$ Os carotenoides possuem espectro de absorção no UV-visível bastante característico, apresentando geralmente três bandas, cuja posição é uma função do número de ligações duplas conjugadas na molécula. ${ }^{18}$ A Figura 5 apresenta os espectros de absorção da solução de padrão de luteína e dos extratos obtidos a partir dos iogurtes adicionados ou não de corante à base de luteína. Foi possível observar que o espectro do extrato do iogurte adicionado de corante apresenta a mesma forma do espectro do padrão de luteína, ambos mostrando comprimentos de onda de absorção máxima a 421, 445 e $473 \mathrm{~nm}$ em etanol. Além disso, o espectro de absorção do extrato do iogurte controle não interferiu nem se sobrepôs ao espectro do extrato do iogurte adicionado de corante na região espectral próxima a $445 \mathrm{~nm}$, atestando a seletividade do método de extração. Caso o iogurte seja totalmente adulterado com outro corante de menor custo, como o carotenoide bixina, o método desenvolvido é capaz de detectar esta fraude facilmente, uma vez que a bixina apresenta características espectrais na região do UV-visível (comprimentos de 
onda de absorção máxima de 429, 457 e 484 nm) diferentes das da luteína. Porém, se a adulteração for parcial, seria necessário utilizar um método de espectrofotometria de derivadas para quantificação como, por exemplo, o desenvolvido para corantes artificiais, ${ }^{27}$ pois estes dois carotenoides são extraídos juntos e a presença de bixina pode levar à superestimação do teor de luteína no iogurte.

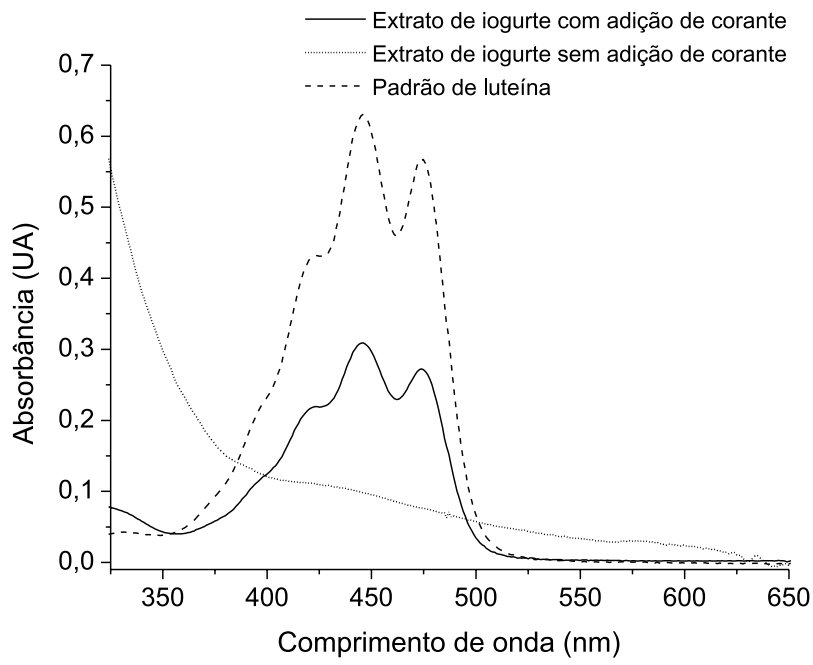

Figura 5. Espectro de absorção no UV-visivel do padrão de luteína $(2,47 \mu \mathrm{g}$ $\left.m L^{-1}\right)$, do extrato obtido a partir do iogurte adicionado de corante à base de luteína e do extrato obtido do iogurte controle

A faixa de linearidade do método foi de 1,41 a 13,42 $\mu \mathrm{g} \mathrm{g}^{-1}$, e os parâmetros da curva analítica são apresentados na Tabela 1. Estes parâmetros foram utilizados para a determinação do LD e LQ, que foram de 0,42 e 1,28 $\mathrm{mg} \mathrm{g}^{-1}$, respectivamente, indicando boa sensibilidade. Dados da literatura apontam um LD inferior $\left(0,014 \mu \mathrm{g} \mathrm{g}^{-1}\right)$ ao encontrado no presente trabalho, ${ }^{28}$ quando realizada a quantificação de luteína em leite e fórmulas pediátricas por CLAE-DAD, provavelmente por se tratar de um método analítico mais sensível que a quantificação por espectrofotometria. Usualmente, a faixa de linearidade de um método, assim como seus LD e LQ, é determinada através de uma curva analítica obtida pela diluição do padrão do composto que se deseja quantificar em solvente. Entretanto, como a matriz estudada pode exercer efeito na quantificação do composto de interesse, é necessário verificar se a faixa de trabalho e os limites estimados pela curva analítica em solvente são coerentes e correspondem aos resultados práticos. No presente trabalho, uma curva analítica foi construída a partir de soluções etanólicas do corante luteína, na faixa de $0,10-1,25 \mu \mathrm{g} \mathrm{mL} \mathrm{m}^{-1}$, correspondente à faixa de concentração dos extratos do iogurte adicionado do corante luteína. Os LD e LQ estimados matematicamente pela curva de diluição do corante foram extremamente baixos, 3,62 × $10^{-16}$ e $1,10 \times 10^{-15} \mu \mathrm{g}$ $\mathrm{mL}^{-1}$, respectivamente, sendo experimentalmente impraticáveis para iogurte, utilizando o método proposto. Por conseguinte, foi empregado o método de superposição de matriz para determinação da faixa de aplicação e limites, construindo-se a curva analítica com extratos obtidos a partir de amostras de iogurte adicionadas de diferentes concentrações de corante luteína. Este método de superposição é utilizado para compensar o efeito da matriz ou possíveis interferentes e fornece uma melhor correspondência com a composição da amostra. Além disso, é desejável que a faixa de aplicação e os limites estejam na mesma unidade dos resultados obtidos pelo método, no caso $\mu \mathrm{g} \mathrm{g}^{-1} .^{13}$

$\mathrm{O}$ valor do DPR, que expressa a repetibilidade do método, foi igual a 3,4\%. Os métodos para análise de compostos presentes em níveis de concentração de $\mu \mathrm{g} \mathrm{g}^{-1}$ devem apresentar DPR inferior a
Tabela 1. Resultados da linearidade do método

\begin{tabular}{lc}
\hline Parâmetros & Resultados \\
\hline Faixa de linearidade & $1,41-13,42 \mu \mathrm{g} \mathrm{g}^{-1}$ \\
Equação: $\mathrm{y}=\mathrm{ax}+\mathrm{b}$ & $\mathrm{y}=0,0274 \mathrm{x}-0,0035$ \\
Coeficiente angular \pm D.P. ${ }^{\mathrm{a}}$ & $0,0274 \pm 0,0030$ \\
Coeficiente linear \pm D.P. & $-0,0035 \pm 0,0144$ \\
Coeficiente de determinação & 0,9938 \\
\hline
\end{tabular}

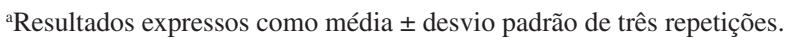

$16 \%{ }^{29}$ Desta forma, o método desenvolvido no presente estudo apresentou um excelente DPR, provavelmente devido ao baixo número de etapas e simplicidade. A exatidão do procedimento analítico foi avaliada por testes de recuperação em três níveis de adição, e variou de 95 a 103\% (Tabela 2). Considerando que os valores de recuperação em todos os níveis testados foram próximos a $100 \%$, o método foi considerado exato.

Tabela 2. Recuperação de luteína nas amostras de iogurte adicionadas de corante à base de luteína

\begin{tabular}{ccc}
\hline $\begin{array}{c}\text { Concentração } \\
\text { adicionada }\left(\mu \mathrm{g} \mathrm{g}^{-1}\right)\end{array}$ & $\begin{array}{c}\text { Concentração } \\
\text { encontrada }\left(\mu \mathrm{g} \mathrm{g}^{-1}\right)^{1}\end{array}$ & Recuperação $^{2}(\%)$ \\
\hline 5,53 & $5,46 \pm 0,31$ & 99 \\
11,49 & $10,96 \pm 0,14$ & 95 \\
13,45 & $13,91 \pm 0,05$ & 103 \\
\hline
\end{tabular}

${ }^{1}$ Resultados expressos como média \pm desvio padrão de três repetições. ${ }^{2} \mathrm{Cal}-$ culada a partir da média da concentração de três repetições.

\section{CONCLUSÃO}

O método proposto para extração e quantificação por espectrofotometria no UV-visível de carotenoides em iogurte adicionado de corante à base de luteína demonstrou seletividade, linearidade na faixa estudada, sensibilidade, precisão e exatidão adequadas. Este novo método se apresenta como uma alternativa mais rápida, de fácil execução e de baixo custo para quantificação de corante à base de luteína adicionado em iogurte.

\section{REFERENCIAS}

1. Mercadante, A. Z. Em Food Colorants: Chemical and Functional Properties; Socaciu, C., ed.; CRC Press: New York, 2008, chap. 6.2.

2. Krinsky, N. I.; J. Nutr. 2002, 132, 540S.

3. Loane, E.; Kelliher, C.; Beatty, S.; Nolan, J. M.; Br. J. Ophthalmol. 2008, 92, 1163 .

4. Mares-Perlman, J. A.; Fischer, A. I.; Klein, R.; Palta, M.; Block, G.; Millen, A. E.; Wright, J. D.; Am. J. Epidemiol. 2001, 153, 424.

5. Bhosale, P.; Serban, B.; Bernstein, P. S.; Arch. Biochem. Biophys. 2009, $483,175$.

6. Loane, E.; Nolan, J. M.; O’Donovan, O.; Bhosale, P.; Bernstein, P. S.; Beatty, S.; Surv. Ophthalmol. 2008, 53, 68.

7. Heyes, K. C.; Pronczuk, A.; Perlman, D.; Am. J. Clin. Nutr. 2001, 74, 211.

8. ht t p ://ww w. acnielsen.com.br/press/documents/ OsProdutosMaisQuentesDoMundo_HB_jun_04.pdf, acessada em Dezembro 2011.

9. Jones, S. T.; Aryana, K. J.; Losso, J. N.; J. Dairy Sci. 2005, 88, 1661.

10. Aryana, K. J.; Barnes, H. T.; Emmick, T. K.; McGrew, P.; Moser, B.; J. Food Sci. 2006, 71, 467.

11. Hulshof, P. J. M.; van Roekel-Jansen, T.; van de Bovenkamp, P.; West, C. E.; J. Food Comp. Anal. 2006, 19, 67. 
12. Biehler, E.; Mayer, F.; Hoffmann, L.; Krause, E.; Bohn, T.; J. Food Sci. 2010, 75, 55 .

13. Ribani, M.; Bottoli, C. B. G.; Collins, C. H.; Jardim, I. C. S. F.; Melo, L. F. C.; Quim. Nova 2004, 27, 771.

14. Kimura, M.; Rodriguez-Amaya, D. B.; Godoy, H. T.; Food Chem. 1990, 35, 187.

15. Rivas, J. D. L.; J. Chromatogr. 1989, 464, 442.

16. De Rosso, V.; Mercadante, A. Z.; J. Agric. Food Chem. 2007, 55, 5062.

17. Piccaglia, R.; Marotti, M.; Grandi, S.; Ind. Crop Prod. 1998, 8, 45.

18. Davies, B. H. Em Chemisty and biochemistry of plant pigments; Goodwin, T. W., ed.; Academic Press: London, 1976, chap. 19.

19. Gau, W.; Ploschke, H.J.; Wünsche, C.; J. Chromatogr. 1983, 262, 277.

20. Nozière, P.; Grolier, P.; Durand, D.; Ferlay, A.; Pradel, P.; Martin, B.; J. Dairy Sci. 2006, 89, 2634.

21. International Conference on Harmonization (ICH); Validation of Analytical Procedures: Methodology, Q2B (CPMP/ICH/281/95), 1995.
22. Barreto, G. P. M.; Fabi, J. P.; De Rosso, V. V.; Cordenunsi, B. R.; Lajolo, F. M.; Nascimento, J. R. O.; Mercadante, A. Z.; J. Food Comp. Anal. 2011, 24, 620 .

23. Faria, A. F.; Hasegawa, P. N.; Chagas, E. A.; Pio, R.; Purgatto, E.; Mercadante, A. Z.; J. Food Comp. Anal. 2009, 22, 196.

24. Khachik, F.; Beecher, G. R.; Whitaker, N. F.; J. Agric. Food Chem. 1986, $34,603$.

25. Wondracek, D. C.; Vieira, R. F.; Silva, D. B.; Costa, T. S. A.; Sano, S. M.; Faleiro, F. G.; Quim. Nova 2012, 35, 180.

26. Rodriguez-Amaya, D.; A guide to carotenoid analysis in food, ILSI Press: Washington, 2001

27. Vidotti, E. C.; Rollemberg, M. C. E.; Quim. Nova 2006, 29, 230.

28. Gill, B. D.; Indyk, H. E.; Int. Dairy J. 2008, 18, 894.

29. Horwitz, W.; Anal. Chem. 1982, 54, 67. 